\title{
Power-HIL Application Analysis of a 3-level Inverter for PMSM Machine
}

\author{
Dávid Kiss ${ }^{1 *}$, István Varjasi ${ }^{1}$ \\ 1 Department of Automation and Applied Informatics, Faculty of Electrical Engineering and Informatics, Budapest University of \\ Technology and Economics, H-1117 Budapest, 2 Magyar Tudósok krt., Hungary \\ * Corresponding author, e-mail: kiss.david@aut.bme.hu
}

Received: 10 June 2020, Accepted: 06 July 2020, Published online: 18 January 2021

\begin{abstract}
Power-HIL simulation is one of the emerging areas in power electronics development nowadays. It offers a convenient test environment for the whole power electronics hardware but eliminates the necessity of motor test benches and rotating machines. Selecting a suitable power amplifier for the simulator is however a challenging task. Switching power supplies can be an interesting option as Power Amplifier, but they have to offer superior power capability and dynamic performance over the DUT (Device Under Test), while maintaining high enough switching frequency to meet the dynamic requirements as well. Using commercially available inverters as Power Amplifiers would be an attractive option, if they can achieve the desired emulation accuracy. This paper investigates the possibility of using a common 3-level inverter with an L-C-L coupling network as a Power Amplifier for a P-HIL simulator, to emulate a PMSM (Permanent Magnet Synchronous Machine) machine.
\end{abstract}

Keywords

power electronics, real-time, simulation, power Hardware-in-the-Loop

\section{Introduction}

Electrical drive development is one of the most complex challenges of power electronics and engineering. It involves the cooperation of professionals from multiple areas, like ECU (Electrical Control Unit) design, power electronics design, Electrical machine design, additional mechanical design, and not to forget the software and control development itself. Each subject has effects on every other, close cooperation is necessary during the whole design process. The development time however is very critical in today's competing market. Tools to ease the workflow, to help the designers to work simultaneously on each part are a necessity. Not to mention the continuous testing on multiple levels of the development and the validation testing before product release $[1,2]$.

Simulation tools are present in the market for many years. Off-line simulation tools can help during the design process. There are tools to validate the electrical schematics (LTSpice, Simetrix, etc.), and to model the behavior of the control algorithms (MATLAB/Simulink). The machine designers can simulate the magnetic and thermal behavior of the electrical machine with various Finite Element Analysis tools (MotorCAD, MagNet, Maxwell, JMAG) and the mechanical engineers can validate the drivetrains and the supporting structures with similar tools (Ansys, Catia, Creo). These off-line simulations however are utilizing high amount of computing power, the real-time execution of them is not feasible [3].

Real-time simulation comes in place when the control of the switching power supply is developed. The validation of the proposed structure and algorithm is possible with the previously mentioned off-line tools, but they are neglecting the behavior and timing of the embedded controller which will be running the control software in the real device. To test the real control ECU, Hardware-inthe-Loop testing solutions are advised. This means, a simulator equipment will be interfaced with the real control ECU, receives the signals generated from the controller, and providing the measurement data and feedback values to it. The return values are calculated with a model of the power electronics circuit, the electrical motor, and in some cases even the mechanical load $[4,5]$. The system is completely transparent for the DUT, there shall be no difference in the behavior between the simulator and the real hardware and use-cases. An approach to validate the 
HIL simulation is described in $[6,7]$. The simulator is usually based on an FPGA to meet the strict timing requirements of the applications. An usual HIL setup can be seen in Fig. 1. With HIL testing, a huge amount of time and cost saving is possible. There is no need to wait for the product prototypes and testbenches. Also high-quality semiconductor switching devices are very expensive and a poorly developed and tested control software can easily damage them. In high power application these faults, unintentional overcurrents and short-circuits can lead to severe material causality and can even endanger human life. Fault mode and fault injection test are also concludable conveniently, without the destruction of the prototypes. Real-time HIL simulation tools are commercially available [8], but many company choose to implement a custom one.

Power level HIL simulation extends this concept to test the power electronics hardware as well. In control level HIL simulation the parasitic effects of the power circuit, the sensor inaccuracy and other deviations from an idealistic device are not taken in account. Thermal behavior related, and climate chamber test are also having to be done with the power circuit included [9-11]. The cost and time saving factor is the possibility to emulate the rotating machine with an electrical load, instead of the manufactured rotating machine mounted on a dyno pad. It also eliminates the risks and danger of testing with the rotating mass, even with high speeds. Fault injection [12], operational limits, and ageing simulations are also simpler with this setup. The architecture of a general P-HIL

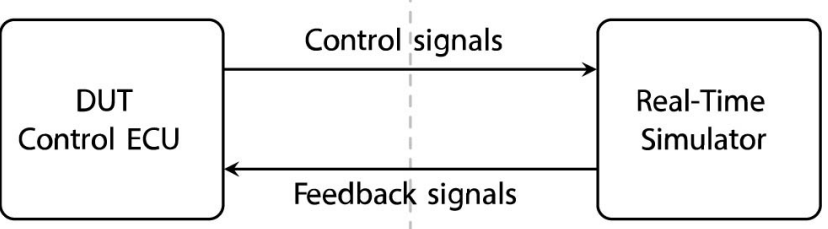

Fig. 1 Hardware-in-the-Loop simulation

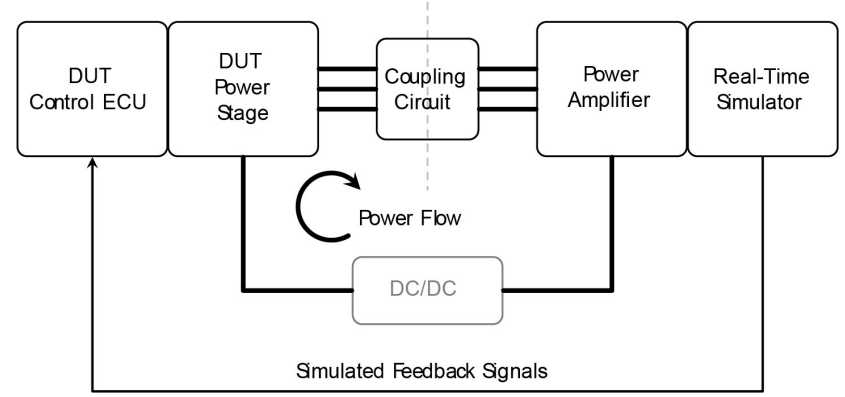

Fig. 2 Power Hardware-in-the-Loop simulation application is shown in Fig. 2. The grey DC/DC converter is an optional part. The power flow is to emphasize the fact, the electrical power is circulating between the DUT and the emulated load, requiring only the losses to be sourced from externel power supply.

The most complex testbench is finally the one with the motor integrated in it, shown in Fig. 3. In this setup the load is usually an electrical machine as well, or some kind of mechanical load (endurance brake for example). Loading with an other electrical machine is convinient due to the felxibility of it, wide variety of load profiles can be tested with the programming of the load machine, both in motor and generator operation. The drawback is the cost and the mechanical maintenance of the pad. Regardless of the mentioned drawbacks, testing with real drivetrain parts shall be the final test of product validation. The circular flow of the power is still true in this architecture as well, however the losses are more significant due to the electrical to mechanical energy conversation, the mechanical coupling between the motors, and finally the mechanical to electrical energy conversation on the load side.

The paper investigates the possibility of emulating a symmetrical PMSM machine on power level. The machine model is a custom developed linear equivalent circuit model, calculating not just the mechanical response of the machine, but the internal EMF (Electromagnetic Force) voltages as well. Saturation and temperature effects are neglected, and the inductances are not dependent on the rotor position $\left(L_{d}=L_{a}\right)$.

This paper organized as follows. The power circuit and the control hardware are introduced in Section 2. The proposed control strategy is described in Section 3. Section 4 will explain the simulation results and the used environment. Finally, Section 5 concludes the results and gives a brief outlook about the authors future work.

\section{The power amplifier}

In case of P-HIL Simulators, the bottleneck is usually the power amplifier. The power capability and the dynamic

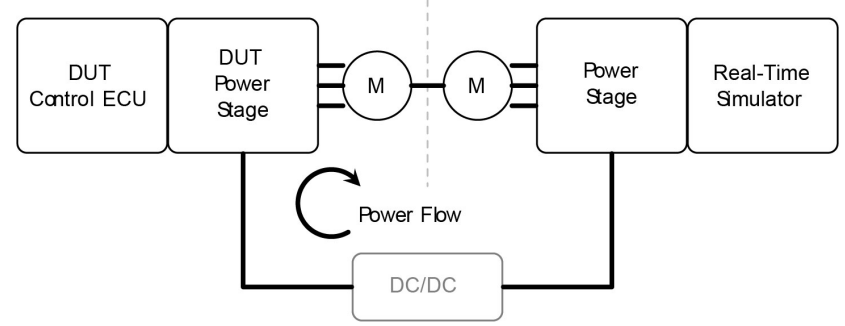

Fig. 3 Testbench with electrical machines 
performance of it is a limiting factor. To accurately replicate the behavior of an electrical machine, the amplifier has to be capable to not just the first harmonics of the motor current and voltage, but higher order harmonics, and inverter switching frequency components as well, especially when the motor parameters are dependent on the rotor position [13, 14].

The paper focuses of a custom-bulit drivetrain laboratory inverter, to investigate the capabilities of the device as a P-HIL Power Amplifier in electrical motor application. The available inverter is a 3-phase 3-level inverter. The maximum available DC Voltage is $800 \mathrm{~V}$ and the switching frequency is $15 \mathrm{kHz}$. The two legs in one phase have inverted carrier signals, meaning there have a $180^{\circ}$ delay between each other, so the apparent switching frequency is two times the PWM carrier frequency $\left(f_{s w}=30 \mathrm{kHz}\right)$.

The configuration and the control strategy make the output voltage resolution smoother as well, the available output voltages are $0 \mathrm{~V}, U_{D C} / 2$ and $U_{D C}$. Each phase is assembled from 2 half-bridge phase-leg, connected with a $L_{i n v}=720 \mu \mathrm{H}$ inductor from each leg to a common $C_{i n v}=300 \mu \mathrm{F}$ output capacitor. The schematic diagram of the inverter is shown in Fig. 4. In each phase the currents of each leg $\left(I_{L 1}, I_{L 2}\right)$, the output current $\left(I_{O U T}\right)$ and the output voltage $\left(U_{c}\right)$ is measured.

The inverter is controlled by a TMS320F335 Texas Instruments microcontroller. For more complex control algorithms and P-HIL modeling, an external FPGA will be connected to the microcontroller via SPI to extend the computational power of the inverter.

To connect the power stage of the DUT to the emulation inverter an external, configurable multi-tapped inductor is used in each phase. In this application the inductor value $\left(L_{S}=560 \mu \mathrm{H}\right)$ was chosen to match the stator inductance of the emulated motor. The output stage of the inverter and the coupling inductor are forming the coupling network, visible $n$ in Fig. 5, in which the emulator inverter is represented with it's Thevenin equivalent circuit.

The goal of the motor emulation is to set the voltage of in each phase to match the Back-EMF voltage and the

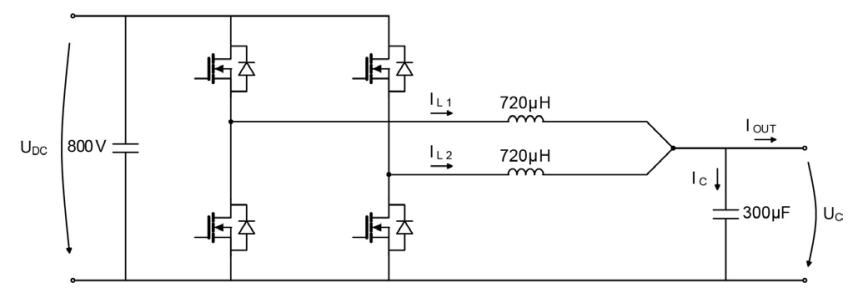

Fig. 4 Schematic of one phase of the proposed inverter

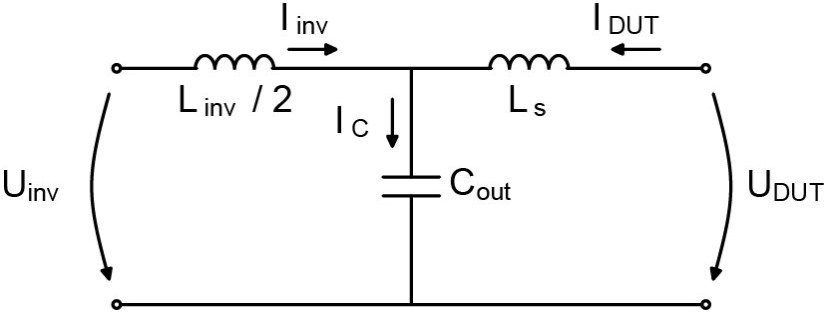

Fig. 5 The coupling network between the P-HIL and the DUT

resistive voltage drop of the emulated machine, while the leakage inductance is represented by the external inductor.

Due to the phase inductance of the machine is embedded into the coupling network via a physical component, it predicts a limitation of the setup. Position dependent motor inductances cannot be emulated with the proposed setup, so the emulated machine must be a non-salient pole three-phase machine. The details of the emulated electrical machine in this paper can be found in Table 1.

The motor parameters were chosen to test the simulation capabilities of the proposed power circuit within it's power limits. The DUT's switching frequency is $5 \mathrm{kHz}$.

\section{Control strategy for the inverter}

The control strategy will be separated in two parts. First the motor model will be introduced, which will source the reference signals for the inverter controller, after that the voltage and current control loop of the inverter will be described. The application suggests the usage of the rotating $d q$ reference frame, which is usual in three-phase applications, therefore all controllers and models are implemented in this way.

\subsection{Emulation motor model}

The emulated motor is a symmetrically magnetized, threephase PMSM machine. The model for the emulation is an equivalent circuit model, with the following assumptions:

- the machine is symmetrical;

- except the copper losses, losses are neglected (no ventilation, no internal friction, no iron losses);

- machine parameters are linear (no saturation and thermal drift).

Table 1 Emulated motor parameters

\begin{tabular}{lcc}
\hline Parameter & Symbol & Value \\
\hline Nominal power & $P_{N}$ & $90 \mathrm{~kW}$ \\
Nominal RMS voltage & $U_{N}$ & $400 \mathrm{~V}$ \\
Nominal frequency & $f_{N}$ & $100 \mathrm{~Hz}$ \\
Winding resistance & $R_{S}$ & $35.6 \mathrm{~m} \Omega$ \\
Winding inductance & $L_{S}$ & $565.8 \mu \mathrm{H}$ \\
Motor inertia & $\theta$ & $0.0912 \mathrm{kgm}^{2}$ \\
Motor pole pairs & $\mathrm{pp}$ & 1 \\
\hline
\end{tabular}


The model is developed in MATLAB/Simulink, without the Simscape Electrical Toolbox. The model is different from a traditional motor models used in electrical drive simulation, in which the model receives the input phase voltages and the outputs are the phase currents and the generated mechanical torque. In this case, because the goal is to emulate the machine Back-EMF voltage, the input is the measured $I_{D U T}$ phase currents, converted to the $d q$ reference frame. The model can also receive the load torque $\left(M_{\text {Load }}\right)$, however in this paper the motor is tested only against it's own inertia, without external load. The output of the motor model is the internal voltage $\left(U_{E M F q}, U_{E M F d}\right)$ in $d q$ reference frame and the motor angular position $(\alpha)$ and speed $(\omega)$. The motor model is shown in Fig. 6.

\subsection{Inverter controller}

The inverter is controlled with a cascaded current and voltage PI controller with feedforward inputs in each stage. The goal of the controller is to set the output capacitor voltage to the requested value by the motor model introduced in Subsection 3.1. The current of the output capacitor is the sum of the inverter and the DUT currents as shown in Eq. (1):

$I_{C}=I_{i n v}+I_{D U T}$.

To overcome the direct effects of the load current on $U_{C}$ the measured $I_{D U T}$ load current is fed forward to the voltage controller, allowing to calculate the desired $I_{i n v}$ current to change the capacitor voltage while sourcing or sinking the $I_{D U T}$ current.

Similarly, in the case of the current controller, to improve the dynamic behavior of the controller, the $U_{i n v}$ output voltage was added to the output of the current controller. The whole control loop is shown in Fig. 7.

\section{Simulation results}

In the test setup a simulated inverter was connected to the off-line model of the proposed P-HIL setup, and to a PMSM machine model as well, but the controller only receives feedback from the P-HIL system. The setup is shown in Fig. 8. The results from the P-HIL and the reference model can be compared this way, however due to reference motor runs without feedback, small position or speed difference over time will lead to desynchronization. Therefore, there is no point to investigate longer simulation runs.

The test profile was a step to mechanical speed reference in the DUT, with a current limit. At first, only the transient response was evaluated. In Fig. 9 the transient response of the P-HIL system is shown, versus the response of a reference motor model. For better observability only one phase is shown. It can be seen, the transient responses are nearly identical, there is a small difference after the start, but later on the two current signals are well aligned.

After the transient response of the P-HIL system was confirmed to meet the requirements, the speed ramping

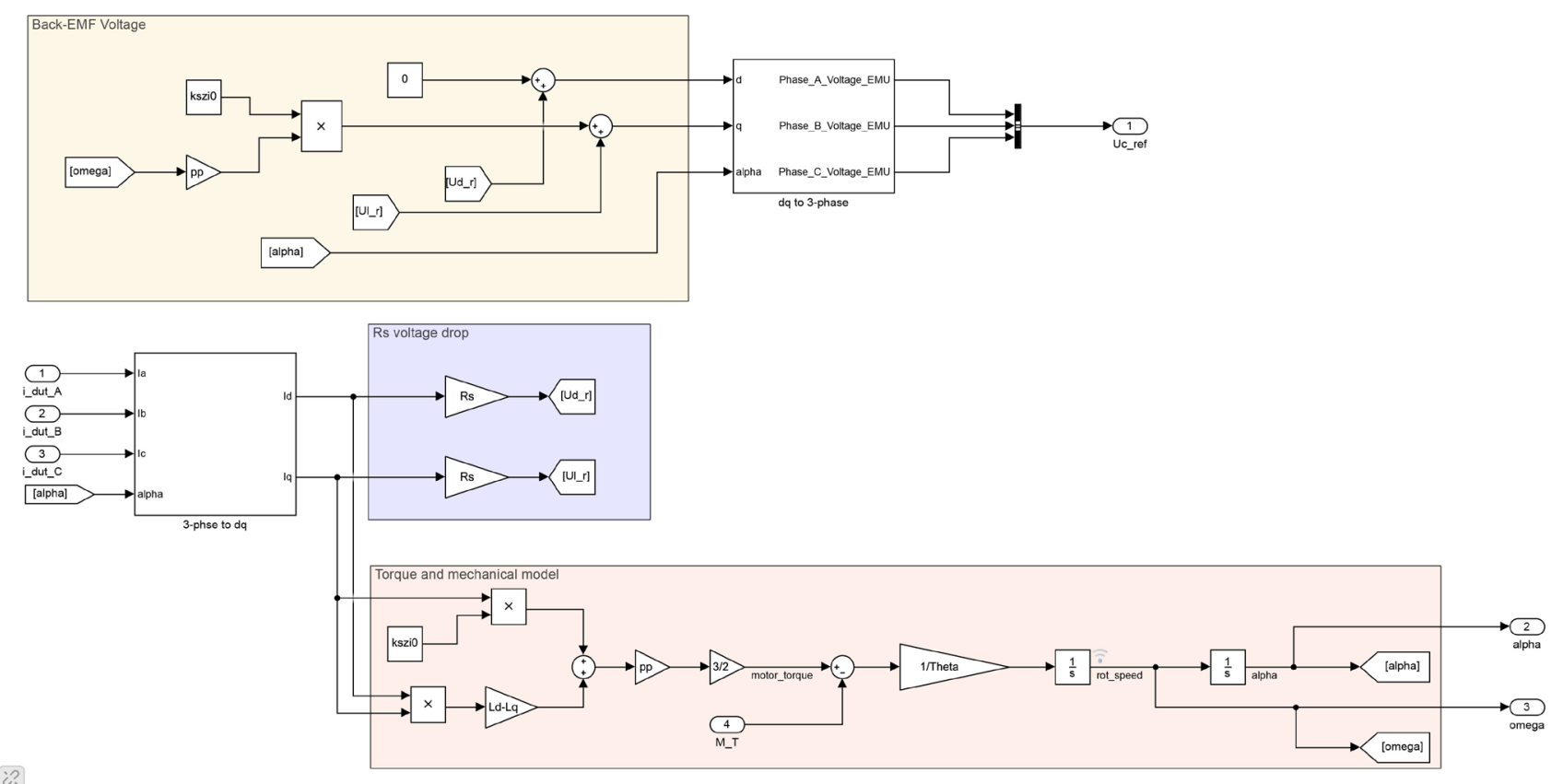

Fig. 6 Motor model for P-HIL Application implemented in MATLAB/Simulink 

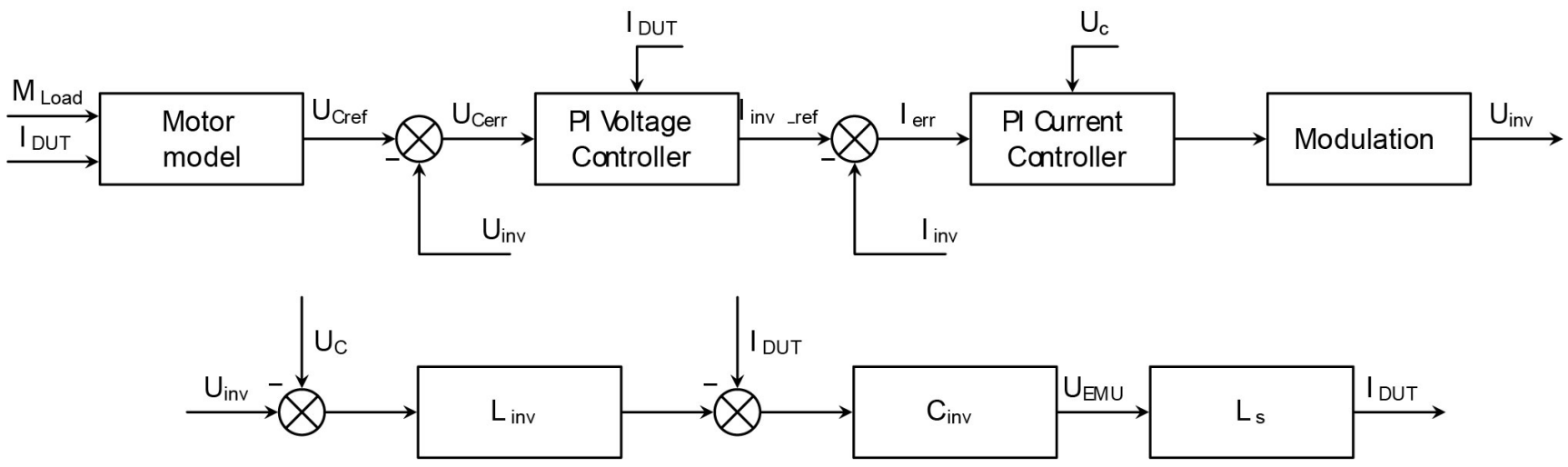

Fig. 7 Control loop for the P-HIL

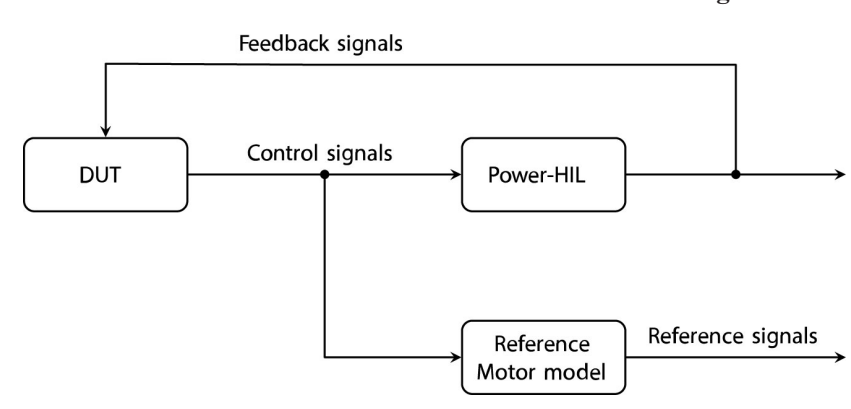

Fig. 8 P-HIL Test setup

of the emulated motor was tested. The simulation was 0.4 seconds long and the motor was accelerated to $500 \mathrm{rad} /$ sec with it's nominal torque. The current waveform of the accelerating machine is shown in Fig. 10.

After the speed setpoint was reached, the current of the motor drops as expected. As comparison the current signals from the reference model are shown in Fig. 11. The comparison between the current waveforms from the P-HIL and the reference motor is satisfactory.
Fig. 12 (a) to (c) shows the error signals derived from the output values from the P-HIL currents and the reference motor currents. The absolute maximum current error is $16 \mathrm{~A}(8 \%)$ during the transient, and it is below 3 .

A when the motor is slow and stays below 6 A during high speeds as well. The position error is oscillating and growing during the whole simulation, which is natural, because only the signals from the P-HIL were fed back to the DUT, therefore the simulation error between the P-HIL and the reference model will add up over time, and the reference motor will fall out of synchronization. The position error also can be the reason behind the growing current error.

\section{Conclusion}

It was shown, the proposed P-HIL simulation setup is suitable to emulate symmetrical PMSM machines. The dynamics of the machine can be reproduced faithfully, and indistinguishably from the DUT's perspective. As a next step, the theoretical limits of the setups shall be defined. Testing on real hardware is also suggested after the off-line validation is succeeded.

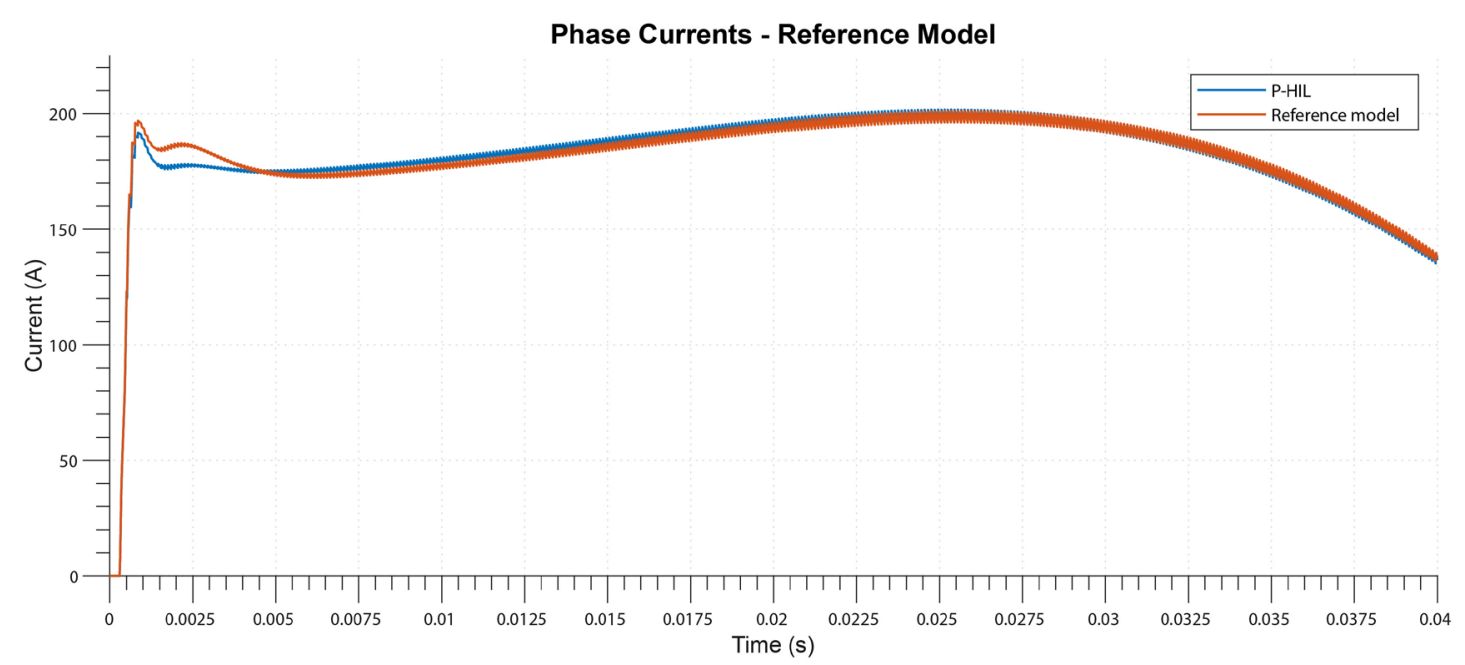

Fig. 9 Transient response of the P-HIL and the reference motor model 
Phase Currents - P-HIL

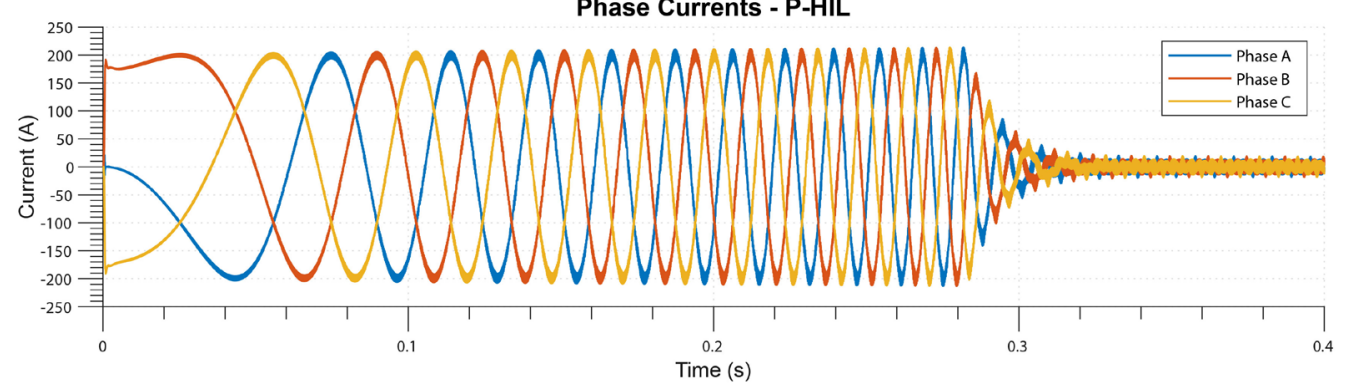

Fig. 10 Speed ramp phase currents of the P-HIL system

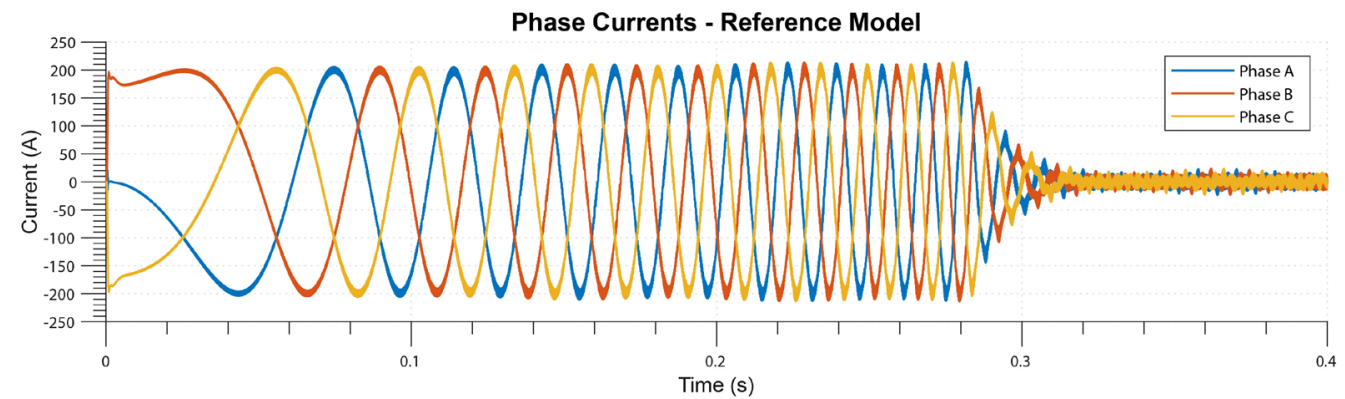

Fig. 11 Speed ramp phase currents of the reference model

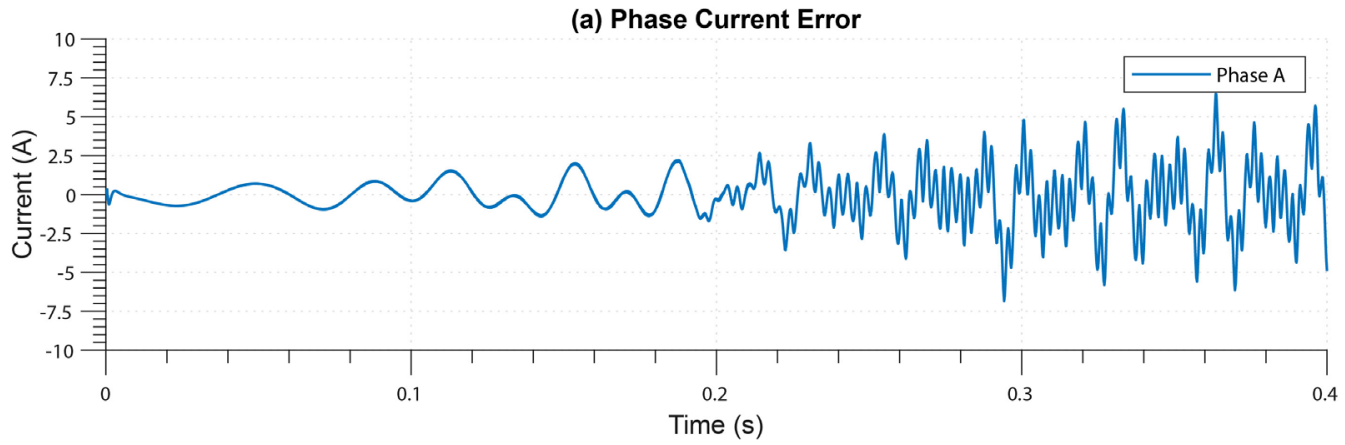

(b) Phase Voltage Error
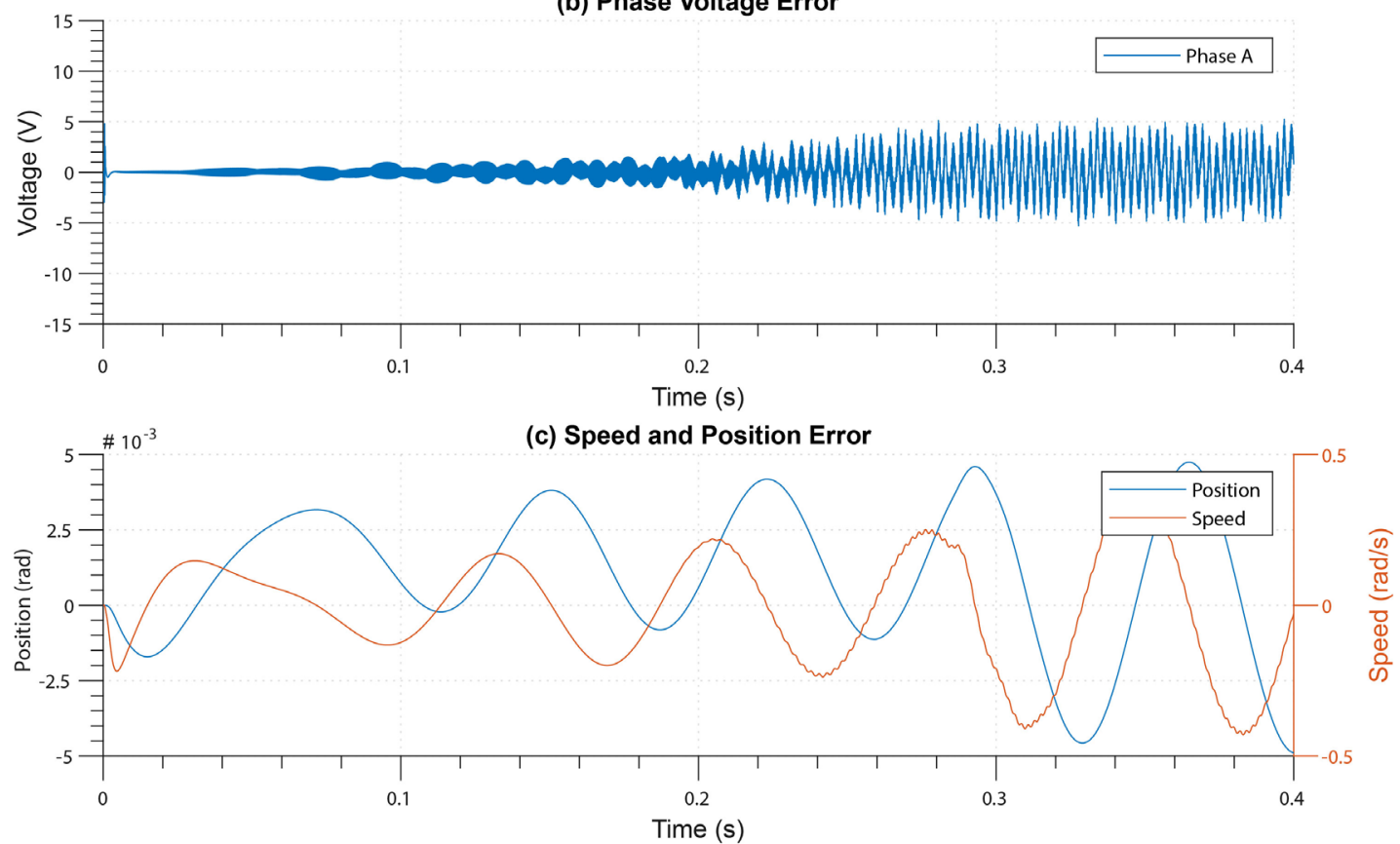

Fig. 12 Error signals (a) Phase Current Error; (b) Phase Voltage Error; (c) Speed and Position Error 


\section{Acknowledgement}

This work was performed in the frame of FIEK_16-1-20160007 project, implemented with the support provided from the National Research, Development and Innovation Fund of Hungary, financed under the FIEK_16.

\section{References}

[1] Farkas, B., Veszprémi, K. "Design of HIL for Multi-Level Inverter Using Zynq-7000 Platform - Part 1", Periodica Polytechnica Electrical Engineering and Computer Science, 61(3), pp. 264-271, 2017.

https://doi.org/10.3311/PPee.10902

[2] Abdelrahman, A. S., Algarny, K. S., Youssef, M. Z. "A Novel Platform for Powertrain Modeling of Electric Cars With Experimental Validation Using Real-Time Hardware in the Loop (HIL): A Case Study of GM Second Generation Chevrolet Volt", IEEE Transactions on Power Electronics, 33(11), pp. 9762-9771, 2018.

https://doi.org/10.1109/TPEL.2018.2793818

[3] Mojlish, S., Erdogan, N., Levine, D., Davoudi, A. "Review of Hardware Platforms for Real-Time Simulation of Electric Machines", IEEE Transactions on Transportation Electrification, 3(1), pp. 130-146, 2017.

https://doi.org/10.1109/TTE.2017.2656141

[4] Bouscayrol, A. "Different types of Hardware-In-the-Loop simulation for electric drives", In: 2008 IEEE International Symposium on Industrial Electronics, Cambridge, UK, 2008, pp. 2146-2151. https://doi.org/10.1109/ISIE.2008.4677304

[5] Dufour, C., Lapointe, V., Belanger, J., Abourdia, S. "Hardware-inthe-loop closed-loop experiments with an FPGA-based permanent magnet synchronous motor drive system and a rapidly prototyped controller", In: 2008 IEEE International Symposium on Industrial Electronics, Cambridge, UK, 2008, pp. 2152-2158.

https://doi.org/10.1109/ISIE.2008.4677105

[6] Kökényesi, T., Varjasi, I. "Validation Method for Hardwarein-the-Loop Simulation Models", In: Koistinen, A., Juuso, E. (eds.) Proceedings of the 9th EUROSIM Congress on Modelling and Simulation, The 57th SIMS Conference on Simulation and Modelling SIMS, Linköping, Sweden, 2018, pp. 749-754. https://doi.org/10.3384/ecp17142749

[7] Kokenyesi, T., Suto, Z., Varjasi, I. "Multilevel Validation Method for Hardware-in-the-Loop Simulation Models", In: 2018 International Symposium on Power Electronics, Electrical Drives, Automation and Motion (SPEEDAM), Amalfi, Italy, 2018, pp. 1346-1351. https://doi.org/10.1109/SPEEDAM.2018.8445273
[8] Dufour, C., Abourida, S., Belanger, J. "Hardware-In-the-Loop Simulation of Power Drives with RT-LAB", In: 2005 International Conference on Power Electronics and Drives Systems, Kuala Lumpur, Malaysia, 2005, pp. 1646-1651.

https://doi.org/10.1109/PEDS.2005.1619952

[9] Kennel, R. M., Boller, T., Holtz, J. "Replacement of electrical (load) drives by a hardware-in-the-loop system", In: International Aegean Conference on Electrical Machines and Power Electronics and Electromotion, Joint Conference, Istanbul, Turkey, 2011, pp. 17-25. https://doi.org/10.1109/ACEMP.2011.6490562

[10] Schmitt, A., Richter, J., Gommeringer, M., Wersal, T., Braun, M. "A Novel 100 kW Power Hardware-in-the-Loop Emulation Test Bench for Permanent Magnet Synchronous Machines with Nonlinear Magnetics", In: 8th IET International Conference on Power Electronics, Machines and Drives (PEMD 2016), Glasgow, UK, 2016, pp. 1-6.

https://doi.org/10.1049/cp.2016.0280

[11] Amitkumar, K. S., Sudharshan Kaarthik, R., Pillay, P. "A versatile power-hardware-in-the-loop based emulator for rapid testing of electric drives", In: 2017 IEEE Energy Conversion Congress and Exposition (ECCE), Cincinnati, OH, USA, 2017, pp. 5468-5474. https://doi.org/10.1109/ECCE.2017.8096913

[12] Aiello, G., Cacciato, M., Scarcella, G., Scelba, G. "Failure analysis of AC motor drives via FPGA-based hardware-in-the-loop simulations", Electrical Engineering, 99(4), pp. 1337-1347, 2017. https://doi.org/10.1007/s00202-017-0630-3

[13] Lentijo, S., D'Arco, S., Monti, A. "Comparing the Dynamic Performances of Power Hardware-in-the-Loop Interfaces", IEEE Transactions on Industrial Electronics Volume, 57(4), pp. 1195-1207, 2010 . https://doi.org/10.1109/TIE.2009.2027246

[14] Sütő, Z., Balogh, A., Kiss, D., Veréb, S., Varjasi, I. "Power HIL Emulation of AC Machines with Parallel Connected ANPC Bridge Arms", In: 2018 IEEE 18th International Power Electronics and Motion Control Conference (PEMC), Budapest, Hungary, 2018, pp. 592-598.

https://doi.org/10.1109/EPEPEMC.2018.8521847 